\title{
Amyloidosis Modifier Genes in the Less Amyloidogenic A/J Mouse Strain
}

\author{
Zhanjun Guo, Masayuki Mori, Xiaoying Fu, Junjie Yao, Yanming Xing, \\ Tatsumi Korenaga, Guixin Li, Takatoshi Matsushita, Masanori Hosokawa, and \\ Keiichi Higuchi
}

\begin{abstract}
Department of Aging Biology (ZG, MM, XF, JY, YX, TK, GL, KH), Shinshu University Graduate School of Medicine, Matsumoto, and The Core Research for Evolutional Science and Technology (ZG, KH), Japan Science and Technology Corporation, Tokyo, and The Field of Regeneration Control (TM), Institute for Frontier Medical Science, Kyoto University, Kyoto, and Department of Pathology (MH), Institute for Developmental Research, Aichi Human Service Center, Kasugai, Japan
\end{abstract}

\begin{abstract}
SUMMARY: Apolipoprotein A-II is deposited as an amyloid fibril in aged mice (senile AApoAll amyloidosis). Although mouse strains with the apolipoprotein A-II $c$ allele $\left(A p o a 2^{C}\right)$ generally develop early-onset and severe senile amyloidosis, the $A / J$ strain shows significantly less amyloid deposition. To identify genes that modify spontaneous amyloidosis development in the A/J mouse, we performed a genome-wide screening using hybrid mice derived from A/J and SAMP1 mice, which have Apoa2 ${ }^{c}$ and age-associated severe amyloid deposition. Our genetic analysis revealed that the lower levels of amyloidosis in the $\mathrm{A} / \mathrm{J}$ strain were polygenically controlled. We found two chromosome locations associated with amyloidosis. One of these regions was in the chromosome 19 telomeric region, where the $\mathrm{A} / \mathrm{J}$ alleles modify amyloidosis in an additive manner. The second region was in the chromosome 4 telomeric region, where the $\mathrm{A} / \mathrm{J}$ alleles modify amyloidosis in a dominant manner. Perlecan and group II secretory phospholipase A2, located on the significantly linked region of chromosome 4, were compared in this study. These findings are for understanding the genetic mechanism of amyloidosis-related diseases and their prevention. (Lab Invest 2003, 83:1605-1613).
\end{abstract}

$A$ myloidosis refers to a group of protein-folding diseases (Westermark, 1998; Xing and Higuchi, 2002). Various proteins, innocuous and soluble under physiologic conditions, polymerize to insoluble amyloid fibrils in several serious diseases, including Alzheimer's disease, type II diabetes, amyloidosis associated with inflammation, kidney dysfunction with chronic dialysis, prion diseases, and familial and sporadic amyloid diseases (Glenner, 1980; Koch, 1992; Serpell et al, 1997). Although the etiology and pathogenesis of amyloidosis are not yet fully understood, drastic structural changes of the amyloid proteins from their normal and soluble forms to the distinctive $\beta$-sheet fibrils may be the most important event in amyloid diseases. Amyloid fibril formation in vivo depends on (i) amyloid protein mutations or variations, (ii) amyloid protein metabolic changes, (iii) aging, (iv) environment, and (v) individual genetics. Identification

DOI: 10.1097/01.LAB.0000098426.35057.73

Received April 17, 2003.

This work was supported by Grants-in-Aid for Priority Areas (15032217 and 15019036) and Scientific Research (B) (114380380) from the Ministry of Education, Culture, Sports, Science and Technology, and by a grant from the Ministry of Health and Welfare of Japan.

Address reprint requests to: Dr. K. Higuchi, Department of Aging Biology, Institute on Aging and Adaptation, Shinshu University Graduate School of Medicine, 3-1-1 Asahi, Matsumoto 390-8621, Japan. E-mail: khiguchi@sch.md.shinshu-u.ac.jp of genes that modify amyloidosis progress (amyloidosis modifier genes) is essential for understanding pathologic events that lead to amyloidosis and for the development of therapeutic and/or preventive treatments.

Mice have been used widely to clarify the molecular mechanisms contributing to amyloidosis pathology. In mouse senile amyloidosis, apolipoprotein A-II (apoAII), the second most abundant apolipoprotein in serum high-density lipoprotein (HDL), polymerizes to amyloid fibrils (AApoAll) and is deposited systemically in almost all tissues, except brain, in an age-related manner (Higuchi et al, 1986, 1991b; Xing et al, 2002). AApoAll amyloidosis has recently been detected in humans (Benson et al, 2001). Three alleles, Apoa2 ${ }^{a}$, Apoa2 $^{b}$, and $A p o a 2^{c}$, which encode three APOA2 protein variants (types $A, B$, and $C$, respectively) that vary at four amino acid positions, have been found among inbred mouse strains (Higuchi et al, 1991a). Generally, Apoa2 ${ }^{C}$ allele mouse strains, including SAMP1, SAMP2, SAMP7, SAMP9, SAMP10, SAMP11, $\mathrm{SJL} / \mathrm{J}$, and $\mathrm{SM} / \mathrm{J}$, develop early-onset and severe AApoAll amyloidosis. In contrast, the $\mathrm{A} / \mathrm{J}$ strain with the Apoa2 ${ }^{C}$ allele is characterized by mild amyloidosis. These findings may imply that genes other than Apoa2 regulate amyloidosis in the $A / J$ strain. In addition to their suppression of spontaneous amyloidosis, $A / J$ mice also show suppression of secondary (AA) amyloidosis experimental induction (Wohlgethan and 
Cathcart, 1979). Suppression of spontaneous and inducted amyloidosis thus makes this strain an ideal animal model for analyzing amyloidosis modifier genes.

In humans, major individual variations in age of occurrence and progression have been observed in several forms of amyloidosis. Identification of amyloidosis suppression genes can be expected to provide new and valuable information. Reverse genetic approaches, especially quantitative trait loci (QTL) analysis, are useful methods for identifying the causal genes for inherited phenotypes. However, success in mapping QTL in humans has been limited by genetic complexity (Risch et al, 2000). Model animals such as the mouse, on the other hand, have the advantage of controlled breeding and have made it possible for us to identify genetic determinants for osteoporosis using the SAMP6 model mouse (Shimizu et al, 1999, 2001, 2002). To identify the amyloidosis modifier genes in the study presented here, we crossed the two inbred strains that have clearly different AApoAll amyloidosis levels and performed a whole genome scan using microsatellite markers to determine the amyloidosis-associated chromosome location in the hybrid progenies. We found that low expression of perlecan and loss of activity of group II secretory phospholipase A2 (sPLA2) may contribute to amyloidosis suppression in $\mathrm{A} / \mathrm{J}$ mice. These results indicate the validity of our approach for the identification of genetic factors that control amyloidosis progression and for the provision of useful information for disease prevention.

\section{Results}

\section{Hybrid Mice Profiles for Amyloidosis}

Amyloid deposits were studied in 12-month-old A/J, SAMP1, and their hybrid mice. Wide-ranging variations in amyloid deposition were observed in the liver, spleen, and heart, with $\mathrm{A} / \mathrm{J}$ mice showing almost no amyloid deposition, $(\mathrm{A} / \mathrm{J} \times \mathrm{SAMP} 1) \mathrm{F}_{2}$ hybrid mice moderate, and $(A / J \times S A M P 1) \times P_{1}$ backcross mice and SAMP1 severe deposition in the liver (Fig. 1, $A$ to $D$ ). As shown in Figure 2A, the amyloid index (Al) mean value was 2.64 in SAMP1 mice, or 4.6 times higher than the 0.57 value in $\mathrm{A} / \mathrm{J}$ mice. The respective $\mathrm{Al}$ values of $(A / J \times S A M P 1) F_{1},(A / J \times S A M P 1) F_{2},(A / J \times$ SAMP1) $\times$ A $/$ backcross, and $(A / J \times S A M P 1) \times P_{1}$ backcross mice were $2.35,1.83,1.46$, and 2.14. All of the findings for the hybrid progenies thus suggest decelerating amyloidosis in $\mathrm{A} / \mathrm{J}$ mice. Because $\mathrm{Al}$ showed no difference by sex $(p>0.10)$ (data not shown), all male and female mice were used for mapping. The Al frequency distribution in the $54 \mathrm{~A} / \mathrm{J} \times$ SAMP1 $F_{2}$ and $76(A / J \times$ SAMP1 $) \times A / J$ backcross mice is shown in Figure 2 ( $B$ and $C$ ), demonstrating that the data do not fit a single recessive, dominant, or additive gene model. Figure 2 thus implies that polygenes control amyloidosis development.

\section{Genome Scan}

Linkage to amyloidosis modifier genes was assessed with Map Manager QT. First, a whole genome scan was performed on $\left(\mathrm{A} / \mathrm{J} \times \mathrm{SAMP} \mathrm{F}_{2}\right.$ intercross mice

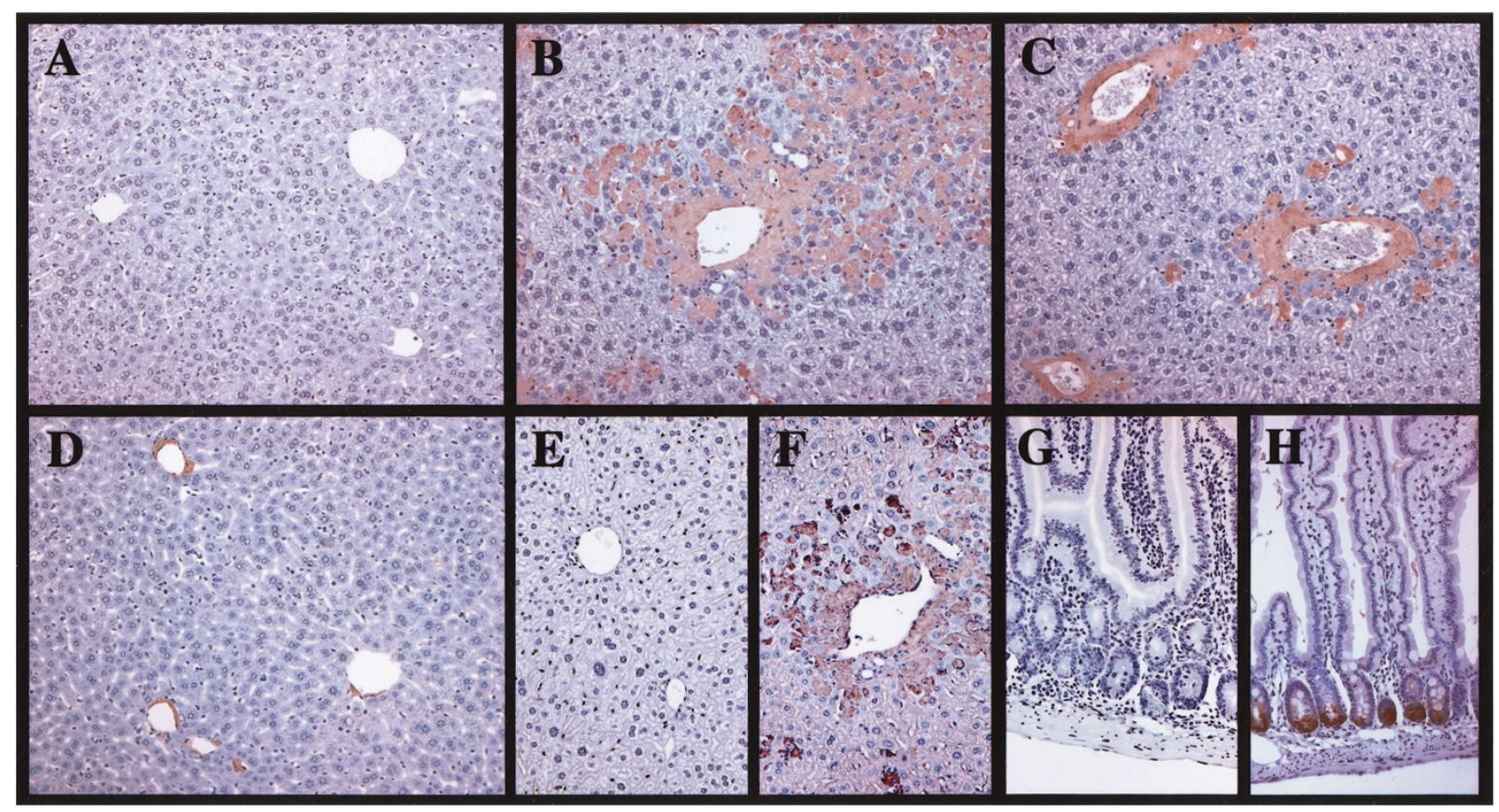

Figure 1.

Immunohistochemically determined differences in amyloid depositions, perlecan, and secretory phospholipase A2 (sPLA2) in 12-month-old A/J, SAMP1, and their hybrid mice. $A, A / J$ liver of AApoAll staining; $B, S A M P 1$ liver of AApoAll staining; $C,(A / J \times S A M P 1) \times S A M P 1$ liver of AApoAll staining; $D,(A / J \times S A M P 1) F_{2}$ liver of AApoAll staining; $E, A / J$ liver of perlecan staining; F, SAMP1 liver of perlecan staining; G, A/J intestine of SPLA2 staining; H, SAMP1 intestine of sPLA2 staining. $\times 200$. 
A

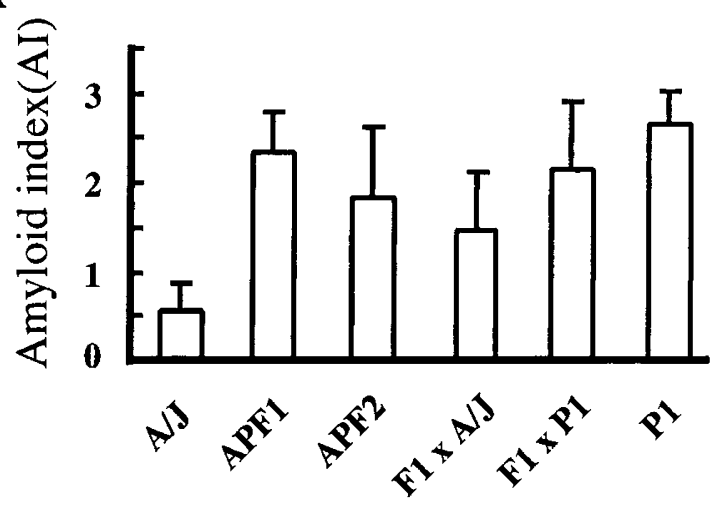

B
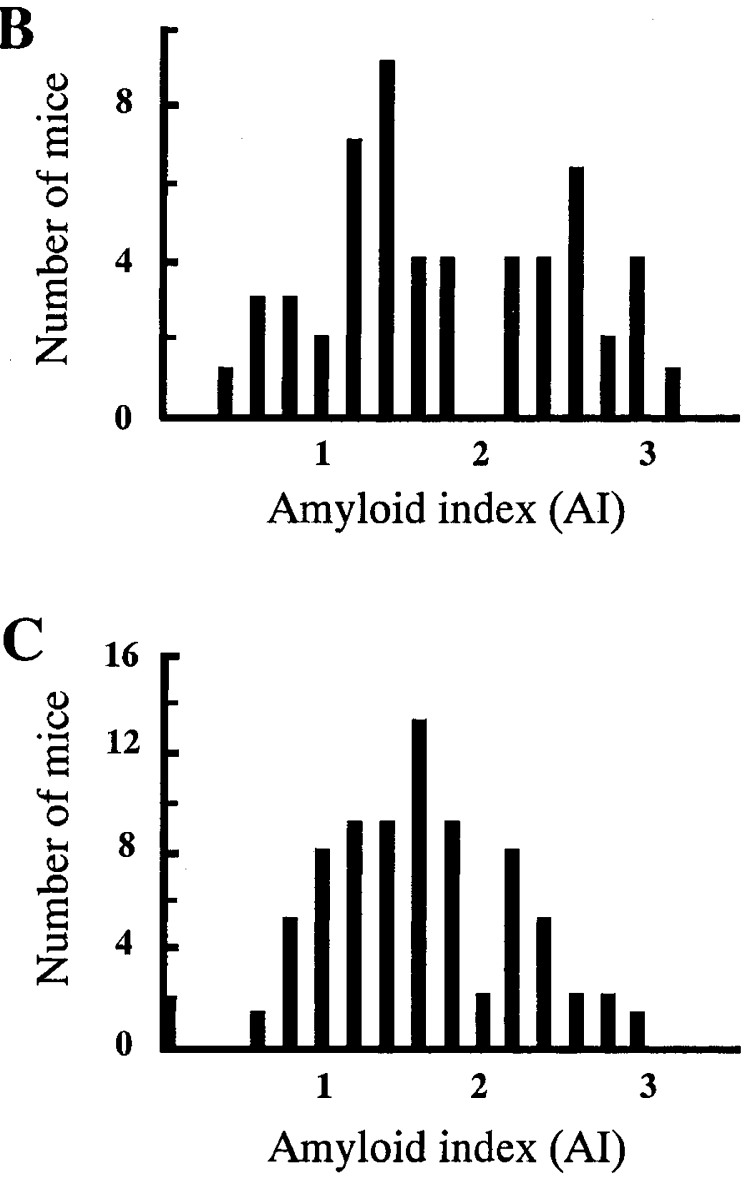

Figure 2.

Amyloid index (AI) in SAMP1 and A/J mice and their hybrids and distribution of $\mathrm{Al}$ in intercrossed and backcrossed hybrid mice. A, Amyloid deposits in 12-month-old A/J and SAMP1 mice and their hybrids. The Al was determined as the average of the grade of amyloid deposits in five organs (liver, spleen, skin, heart, and stomach). B, Al distribution in 54 intercrossed (A/J $\times$ SAMP1) $F_{2}$ mice. C, Al distribution in 76 backcrossed $(A / J \times S A M P 1) \times A / J$ mice. Bars indicate the number of mice used for the genome scan at matched Al levels.

and the likelihood ratio statistics (LRS) were calculated. D2Mit133 on chromosome 2 (66.8 cM), D4Mit32 on chromosome 4 (69.2 cM), and D19Mit67 on chromosome $19(43 \mathrm{cM})$ showed association with amyloidosis (Al) at significant (LRS > 15.2) or suggestive (LRS $>$ 8.8) levels. Additional microsatellite loci were then typed in these regions. The susceptible loci influencing $\mathrm{Al}$ are listed in Table 1. As Table 1 and Figure $3 \mathrm{~A}$ demonstrate, the significant linkage (LRS > 15.2) was seen on chromosome 4 from D4Mit32 $(69.8 \mathrm{cM})$ to D4Mit33 $(79.0 \mathrm{cM})$. The A/J allele significantly slowed down amyloidosis in a dominant manner. The LRS increased sharply, and the peak LRS of 31.3 was attained at D4Mit33 in the distal telomere region. We could not examine regions more distal from D4Mit33 because polymorphic markers were unavailable. One amyloidosis-associated region at the suggestive level with a maximum LRS of 11.5 was found on chromosome 19 (Fig. 3B). The $\mathrm{A} / \mathrm{J}$ alleles in this region showed an additive decelerating effect on amyloidosis. The locus on chromosome 2 with a maximum LRS of 11.0 also seemed to be amyloidosis-linked, with its $\mathrm{A} / \mathrm{J}$ alleles accelerating amyloidosis.

During the second mapping, we genotyped the suspected loci on chromosomes 2 and 19 in the 76 $\left(\mathrm{A} / \mathrm{J} \times \mathrm{P}_{1}\right) \times \mathrm{A} / \mathrm{J}$ backcross mice to verify amyloidosis linkage, but we were unable to find any LRS suggestive of such a linkage on chromosome 2 . The highest LRS score of 12.4 on chromosome 19 was obtained at D19Mit2; no further genetic information could be obtained in this region because other polymorphic markers were unavailable.

Genetic analysis using intercross and backcross hybrid mice from A/J and SAMP1 mice resulted in the identification of two amyloidosis-associated regions, with the $\mathrm{A} / \mathrm{J}$ alleles exhibiting an amyloidosisdecelerating effect. The region on chromosome 4 showed dominant linkage, and the one on chromosome 19 showed additive linkage.

\section{Candidate Gene Analysis}

Candidate genes from the telomeric region of chromosomes 4 and 19 were analyzed. Perlecan (heparan sulfate proteoglycan 2; Hspg2) at $71.4 \mathrm{cM}$ on chromosome 4 (http:www.infomatics.jax.org/ccr) was used for comparative analysis. Perlecan is a basement membrane heparan sulfate proteoglycan identified in almost all amyloids (Kisilevsky et al, 1995). A 503-bp region within domain I of $H s p g 2$ cDNA was amplified from the kidney and liver of 6-month-old female $\mathrm{A} / \mathrm{J}$ and SAMP1 mice by means of RT-PCR (Fig. 4). Although PCR products could be obtained from the liver and kidney in SAMP1 mice, no band could be obtained from A/J mice. To identify the genetic differences responsible for this expressional variation, we amplified the entire Hspg2 gene (12 kb) from ovarian cDNA and compared the sequence of these two strains, but we could find no mutations that might cause an amino acid substitution.

Group II sPLA2 at $68 \mathrm{cM}$ (Pla2g2a) on chromosome 4 (Fig. 3A) was also analyzed. Genomic DNA was amplified by PCR, and the nucleotide sequences of all Pla2g2a exons of the SAMP1 and A/J mice were compared. In exon 3, a thymidine insertion at $166 \mathrm{bp}$ downstream from the putative translation start codon was identified in the $\mathrm{A} / \mathrm{J}$ mouse (Fig. 5). The " $\mathrm{t}$ " insertion induces a frameshift, resulting in a truncated 
Table 1. Summary of Susceptible Loci Influencing Amyloidosis In $(A / J \times P 1) F_{2}$ Mice

\begin{tabular}{|c|c|c|c|c|c|c|}
\hline Locus & Position & $\mathrm{LRS}^{a}$ & Effect $^{b}$ & $\mathrm{Al}^{c}(\mathrm{~A})$ & $\mathrm{Al}(\mathrm{H})$ & $\mathrm{Al}(\mathrm{P})$ \\
\hline D2Mit295 & $17 \mathrm{cM}$ & 8 & Additive $\uparrow$ & $2.16(n=18)$ & $1.67(n=21)$ & $1.48(n=15)$ \\
\hline D2Mit133 & $66.8 \mathrm{cM}$ & 11 & Recessive $\uparrow$ & $2.53(n=8)$ & $1.73(n=25)$ & $1.55(n=21)$ \\
\hline D2Mit309 & $71 \mathrm{cM}$ & 7.5 & Recessive $\uparrow$ & $2.38(n=9)$ & $1.63(n=35)$ & $1.74(n=10)$ \\
\hline D2Mit257 & $75 \mathrm{cM}$ & 10.3 & Recessive $\uparrow$ & $2.53(n=8)$ & $1.64(n=24)$ & $1.66(n=22)$ \\
\hline D2Mit258 & $78 \mathrm{cM}$ & 10.3 & Recessive $\uparrow$ & $2.53(n=8)$ & $1.64(n=24)$ & $1.66(n=22)$ \\
\hline D2Mit227 & $98 \mathrm{cM}$ & 4 & Recessive $\uparrow$ & $2.20(n=10)$ & $1.67(n=35)$ & $1.71(n=9)$ \\
\hline D4Mit89 & $18.9 \mathrm{cM}$ & 6.7 & Additive $\downarrow$ & $1.30(n=10)$ & $1.77(n=24)$ & $2.03(n=20)$ \\
\hline D4Mit32 & $69.8 \mathrm{cM}$ & 16.4 & Dominant $\downarrow$ & $1.37(n=7)$ & $1.59(n=33)$ & $2.41(n=14)$ \\
\hline D4Mit13 & $71 \mathrm{cM}$ & 22.6 & Dominant $\downarrow$ & $1.48(n=8)$ & $1.55(n=33)$ & $2.55(n=13)$ \\
\hline D4Mit160 & $76 \mathrm{cM}$ & 26.6 & Dominant $\downarrow$ & $1.48(n=8)$ & $1.54(n=34)$ & $2.65(n=12)$ \\
\hline D4Mit129 & $76.6 \mathrm{cM}$ & 27.6 & Dominant $\downarrow$ & $1.70(n=10)$ & $1.48(n=32)$ & $2.65(n=12)$ \\
\hline D4Mit33 & $79 \mathrm{cM}$ & 31.3 & Dominant $\downarrow$ & $1.77(n=13)$ & $1.41(n=29)$ & $2.67(n=12)$ \\
\hline D5Mit80 & $26 \mathrm{cM}$ & 4.1 & Additive $\downarrow$ & $1.55(n=15)$ & $1.76(n=19)$ & $2.11(n=17)$ \\
\hline D19Mit69 & $6 \mathrm{cM}$ & 4.9 & Additive $\downarrow$ & $1.51(n=14)$ & $1.73(n=26)$ & $2.15(n=12)$ \\
\hline D19Mit16 & $15 \mathrm{cM}$ & 4 & Additive $\downarrow$ & $1.57(n=15)$ & $1.79(n=27)$ & $2.01(n=11)$ \\
\hline D19Mit67 & $43 \mathrm{cM}$ & 11.5 & Additive $\downarrow$ & $1.18(n=8)$ & $1.73(n=32)$ & $2.23(n=14)$ \\
\hline D19Mit2 & $51 \mathrm{cM}$ & 7.3 & Recessive $\downarrow$ & $1.50(n=10)$ & $1.64(n=28)$ & $2.19(n=16)$ \\
\hline
\end{tabular}

${ }^{a}$ When significant association was detected with more than two models at the same locus, the highest LRS was adopted.

${ }^{b}$ Effect of $\mathrm{A} / \mathrm{J}$ allele on amyloidosis, either decelerative $(\downarrow)$ or accelerative $(\uparrow)$.

${ }^{c} \mathrm{Al}$ represents mean value of the amyloid index of parent-derived alleles at the various loci. Fifty-four mice from $(A / J \times S A M P 1) F_{2}$ hybrid progenies were used. A designates the A/J-derived allele, $\mathrm{H}$ designates the heterozygous allele from SAMP1 and A/J, and P designates the SAMP1-derived allele.

\section{A $\quad \operatorname{Chr} 4$}

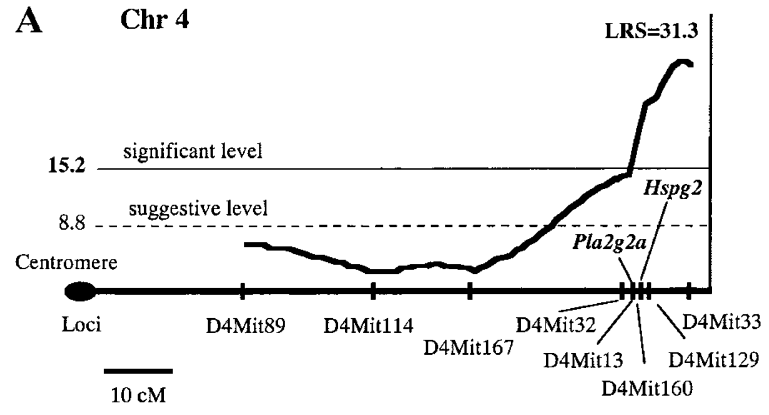

\section{B Chr 19}

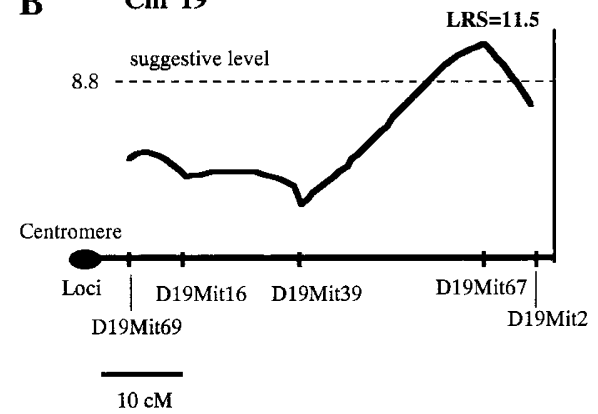

Figure 3.

Calculation of likelihood ratio statistics (LRS) for Al on chromosomes 4 and 19 detected with microsatellite markers in intercrossed hybrid mice. The $\mathrm{CM}$ scales along the $x$ axis start at the centromeres and move toward the telomeres. The $y$ axis indicates LRS for intervals containing putative quantitative trait loci (QTL) affecting amyloid deposits calculated on the basis of the free genetic model. A, Loci on chromosome 4, Pla2g2a and Hspg2 represent group II SPLA2 and perlecan. B, Loci on chromosome 19.

sPLA2. Because the insertion results in the loss of a $\mathrm{BamHI}$ site, this BamHI polymorphism was used for the genotyping of several mouse strains for the Pla2g2a locus. This frameshift mutation was not found

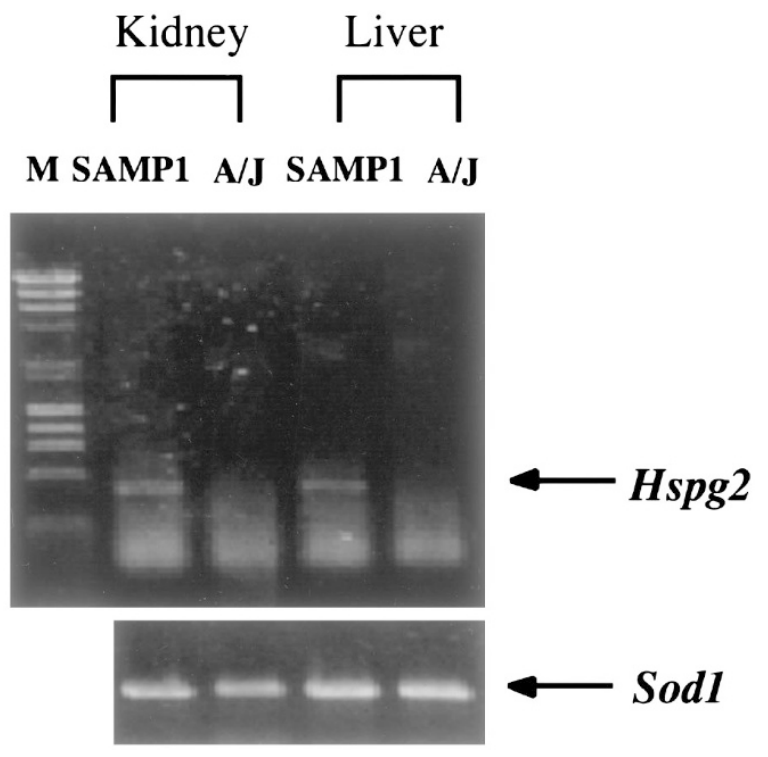

Figure 4.

Reduced expression of Hspg2 in the A/J mouse. RT-PCR of kidney and liver of 6-month-old A/J and SAMP1 mice was performed with primer pairs spanning 503 bp. Superoxide dismutase 1 (Sod1) was used as a control. A comparison with the weak PCR band in SAMP1 tissues indicates that Hspg2 mRNA was undetectable in the $\mathrm{A} / \mathrm{J}$ mouse.

in amyloidosis-sensitive strains with the Apoa2 ${ }^{C}$ allele, comprising the SAMP1, SAMP2, SAMP7, SAMP10, SJL/J, and SM/J mice. QTL analysis at the Pla2g2a locus showed significant linkage, with an LRS of 17.6 .

The influence of the truncated SPLA2 on apoA-II metabolism was studied by means of inflammatory stimulation with an $\mathrm{AgNO}_{3}$ injection. As shown in Figure 6A, Pla2g2a mRNA expressional levels in SAMP1 mice, which were moderate in the normal 


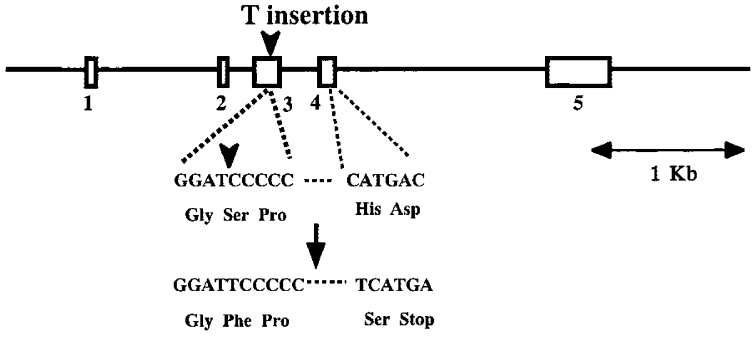

Figure 5.

Genomic organization of the mouse Pla2g2a gene. The exons are indicated by the number below the corresponding box. The T insertion that causes the loss of the BamHI restriction site in exon 3 is shown by an arrowhead. The gene of the $\mathrm{A} / \mathrm{J}$ mouse is truncated in exon 4 because of this insertion.

state, had increased dramatically 24 hours after induction. However, Pla2g2a mRNA could not be detected by RT-PCR in A/J mice after $\mathrm{AgNO}_{3}$ induction. At 24 hours after induction, the apoA-Il levels in the HDL particles of SAMP1 mice were reduced to $65 \%$ of the level before stimulation, subsequently increased to $80 \%$ at 72 hours, and then decreased again to $65 \%$ at 168 hours. The apoA-II protein levels in A/J HDL particles changed only slightly after induction. The differences in HDL-apoA-II levels between SAMP1 and $\mathrm{A} / \mathrm{J}$ mice at 24 and 168 hours after induction were significant ( $p<0.05$; Fig. 6B). The total apoA-II protein levels in circulation show almost the same pattern as that in HDL particles in SAMP1 and A/J mice (Fig. 6C). Examination of the plasma SAA levels showed that SAMP1 and A/J mice displayed the same pattern of change after inflammatory induction: a sharp increase at 24 hours followed by a return to normal levels, and then becoming almost undetectable at 168 hours. The SAA levels at the start of induction and those at subsequent time points showed no statistically significant differences between the two strains (data not shown). The HDL size as a parameter for HDL metabolism showed an increase at 24 hours after induction, a peak at 48 hours, and then a return to normal levels at 168 hours in both SAMP1 and A/J mice. No HDL size strain-dependent differences were found (data not shown).

\section{Discussion}

The major genetic factors that control the progression of amyloidosis are the genes coding amyloid proteins. Mutations in the $A \beta$ precursor protein, transthyretin, and other amyloid proteins result in severe amyloidosis. One allele of human SAA1 and PRNP (prion protein) has been found to increase amyloidosis susceptibility (Baba et al, 1995; Carlson et al, 1986). Genetic and environmental factors may modify the progression of various types of amyloidosis, but the specific modifier genes that control amyloid fibril formation and amyloidosis progression remain elusive. Variations in spontaneous AApoAll amyloidosis progression among inbred mouse strains has made the genetic analysis of amyloidosis possible. To avoid any strong effects from the Apoa2 coding region upon our
A

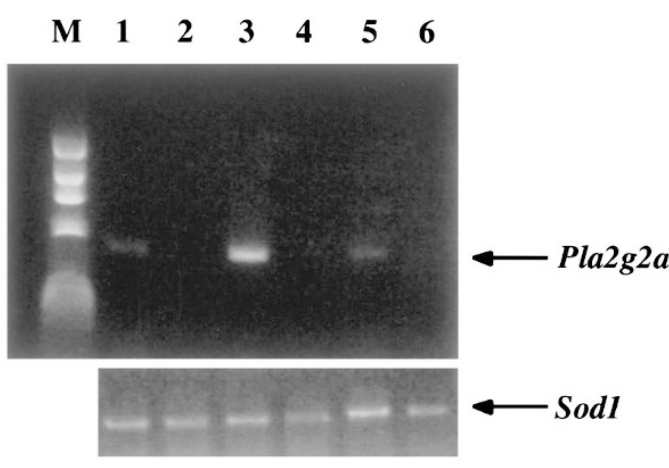

B
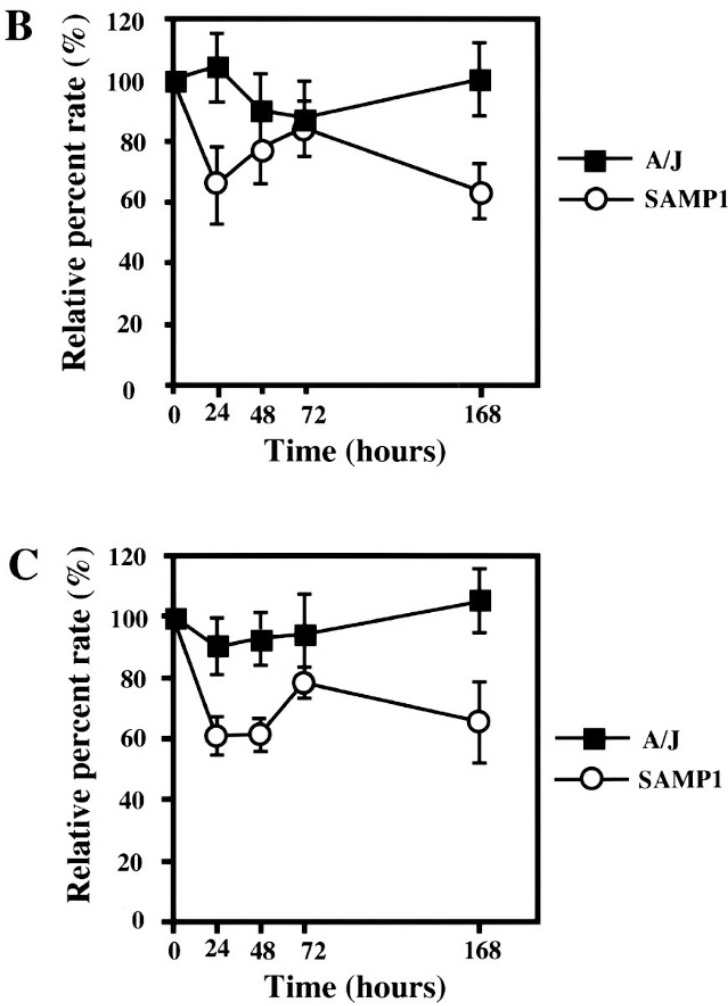

Figure 6.

Reduced apolipoprotein A-II (apoA-II) protein levels in SAMP1 plasma after sPLA2 induction. A, Constitutive and increased expression of Pla2g2a mRNA in SAMP1 mice after $\mathrm{AgNO}_{3}$ injection. RT-PCR for intestinal mRNA from male 3-month-old SAMP1 and A/J mice was performed with primer pairs spanning 530 bp of Pla2g2a cDNA. Sod1 was used as a control. Lane1: SAMP1, 0 hour; lane 2: A/J, 0 hour; lane 3: SAMP1, 24 hours; lane 4: A/J, 24 hours; lane 5: SAMP1, 168 hours; lane 6: A/J, 168 hours after $\mathrm{AgNO}_{3}$ injection. B and C, Differences in apoA-II metabolism between male 3-month-old SAMP1 and A/J mice $(n=8)$ after SPLA2 induction. apoA-II levels were quantified by Western blot analysis using anti-AApoAll antibodies. The apoA-II protein levels were similar in SAMP1 and A/J mice before induction $(55.91 \pm 5.01 \mathrm{mg} / \mathrm{dl}$ in SAMP1 and $57.16 \pm 4.50 \mathrm{mg} / \mathrm{dl}$ in A/J). The mean value and SE for the relative percentage change in the protein levels at different time points versus the initial protein levels were compared in SAMP1 and A/J mice. B, apoA-II levels in high-density lipoprotein (HDL) particles of SAMP1 (O) and A/J ( $\square$ ) mice after sPLA2 induction. C, Total apoA-II in plasma of SAMP1 (O) and A/J (ם) mice after SPLA2 induction.

analysis, we used SAMP1 and A/J mouse strains, both of which carry the amyloidogenic Apoa2 ${ }^{C}$ allele.

We identified two chromosome locations responsible for low amyloidosis levels in A/J mice: one, which seems to act in an additive manner, on chromosome 
19; and the other, which seems to act in a dominant manner, on chromosome 4. Genetic factors affecting spontaneous amyloidosis in the $\mathrm{A} / \mathrm{J}$ mouse were previously reported by Chai and Lerner (1985). They crossed the high-incidence LLC strain with AVJ mice, both of which possess the Apoa2 ${ }^{C}$ allele (Higuchi et al, 1991a), and produced $F_{1}, F_{2}$, and backcross generations. They concluded that the low incidence of spontaneous amyloidosis was controlled in an additive manner by a locus in the A/J mice (Chai and Lerner, 1985). Given the genetic differences between LLC and SAMP1 mice, these findings are consistent with our results. The additive loci on chromosome 19 identified in our study may correspond to the additive locus found by Chai and Lerner. This locus may reflect the generally low-level amyloidosis characteristic of and specific to $\mathrm{A} / \mathrm{J}$ mice.

The telomere region of chromosome 4 with the highest LRS (>31.3) was significantly linked to amyloidosis. Although the intervals showing significant associations with amyloidosis were large (Fig. 3A), we were able to analyze two candidate genes, Hspg2 and Pla2g2a. Significant advances in understanding the mechanism of amyloidogenesis have emerged from immunohistochemical studies that have demonstrated codeposition of the basement membrane form of heparan sulfate proteoglycan and amyloid (Lyon et al, 1991; Snow and Kisilevsky, 1985). In addition, perlecan has been found to play a role in $A \beta$-fibril formation and to stabilize amyloid fibrils once they are formed (Castillo et al, 1997; Woodrow et al, 1999). No amino acid substitution for perlecan was identified in $\mathrm{A} / \mathrm{J}$ and SAMP1 mice, but reduced expression was detected in 6-month-old A/J mice. The perlecan staining was performed in tissue sections of 12-month-old $\mathrm{A} / \mathrm{J}$, SAMP1 and their hybrid mice; it was present in substantial quantity in the amyloid deposits at the SAMP1 liver (Fig. 1, E and F). A thorough analysis of promoter activity is needed to further clarify the amyloidosis suppression mechanism in $\mathrm{A} / \mathrm{J}$ mice.

Poor expression, truncated protein, and loss of SPLA2 activity as a result of "t" insertion have been identified in $\mathrm{A} / \mathrm{J}$ and C57BL/6J mice (Kennedy et al, 1995). This frameshift mutation was not found, however, in amyloidosis-sensitive strains possessing Apoa2 ${ }^{C}$. SPLA2 is an acute phase protein, so that SPLA2 plasma levels are significantly increased in both acute and chronic inflammation, including acute pancreatitis, rheumatoid arthritis, and asthma (Bowton et al, 1997; Vadas et al, 1993). Lipoproteins such as HDL are substrates for SPLA2 (Pruzanski et al, 1998), and SPLA2 overexpression causes rapid catabolism, reduces the concentration, and enhances tissue uptake of HDL (Pruzanski et al, 1995; Tietge et al, 2000). sPLA2 is mainly expressed in the intestine (MacPhee et al, 1995). It located in the small intestinal gland of the fundus in SAMP1 mice (Fig. $1 \mathrm{H}$ ) but undetected in that of $\mathrm{A} / \mathrm{J}$ mice (Fig. 1G). SPLA2 may be secreted from the intestine to the lymphatic system to eventually reach the circulatory system, where it influences HDL metabolism. sPLA2 is also synthesized in the vascular smooth muscle cells (Nakano et al, 1990). In mice, apoA-II has been identified as a major molecule that controls HDL metabolism (Mehrabian et al, 1993; Wang et al, 1997). An age-associated decrease in the concentration and acceleration of plasma apoA-II and HDL turnover are distinct features of SAMP1 lipid metabolism (Kitagawa et al, 1994; Naiki et al, 1988). Upon induction of sPLA2 by inflammation, HDLapoA-II displays a different metabolism in the two strains (Fig. 6). Although these findings are far from conclusive, it seems likely that the increase in SPLA2 accelerates apoA-II release from $\mathrm{HDL}$ and that these free apoA-II proteins are then taken up by tissues to favor amyloid deposition in SAMP1 mice but not in AVJ mice. The changes in size of SAA and HDL are almost the same in $\mathrm{A} / \mathrm{J}$ and SAMP1 mice after induction, which excludes the possibility that the difference in apoA-II metabolism is caused by a difference in the response to stimulation by SAMP1 and A/J mice.

It has been shown that SPLA2 has high affinity for heparan sulfate proteoglycan and the later in turn increases activity of the former (Hurt-Camejo et al, 1997; Sartipy et al, 1996). As a heparan sulfate proteoglycan, perlecan possibly interact directly with sPLA2 in modifying amyloidosis development.

We reanalyzed the amyloidosis-related chromosomal regions suggested by the findings for $(A / J \times$ SAMP1)F $F_{2}$ intercross mice by using newly developed $\left(F_{1} \times A / J\right)$ backcross mice. No dominant locus could be analyzed with this mating system, and we did not observe any linkage on chromosome 4. However, we could determine the locus of the linkage on chromosome 19 (D19Mit 67, $43.0 \mathrm{cM}$ and D19Mit2, $51 \mathrm{cM}$ ). The highest LRS of 12.4 was detected at D19Mit2, followed by 12.1 at D19Mit67. The consistent linkage in intercrossed and backcrossed generations proved the validity of these suggestive amyloidosisassociated regions.

In this study we were able to identify the genetic factors that modified senile (AAopAII) amyloidosis development in the $\mathrm{A} / \mathrm{J}$ mouse. Our results indicated that two chromosome locations were associated with the low amyloidosis level in the $\mathrm{A} / \mathrm{J}$ mouse. However, these two QTLs account for only $58 \%$ of the differences in the amyloid deposits between $\mathrm{A} / \mathrm{J}$ and SAMP1 mice. It may be possible to identify other weak QTLs by increasing the sample size. Although it is clear that the Hspg2 and Pla2g2a genes on the significantly linked region on chromosome 4 may contribute to amyloidosis susceptibility, further studies are necessary to fully understand the role of these two genes in amyloidogenesis. Precise identification of the genetic factors in amyloidosis patients is important for understanding the mechanisms of the amyloidosis process and individual differences in the symptoms of these mechanisms. Moreover, identification of genes with modifying effects on amyloidosis would be valuable for the prevention and treatment of amyloidosis. Our findings suggest that inflammation may play a role in amyloidosis. Thus, further reverse genetic approaches using hybrid mice from suitable parental strains may provide new insights for amyloidosis research. 


\section{Materials and Methods}

\section{Animals}

SAMP1 mice were maintained by sister-brother mating in the Laboratory of Animal Experiments for Regeneration, Institute for Frontier Medical Science, Kyoto University. A/J mice were purchased from Japan SLC, Inc. (Hamamatsu, Japan). $F_{1}($ SAMP1 $\times$ A $/$ J) and $F_{2}\left(F_{1} \times F_{1}\right)$ hybrid mice and backcrossed mice $\left(F_{1} \times\right.$ SAMP1 and $\left.F_{1} \times A / J\right)$ mice were bred and then raised under conventional conditions at $24^{\circ} \mathrm{C} \pm 2^{\circ} \mathrm{C}$ at the same laboratory as the SAMP1 mice. A commercial diet (CE-2; Nihon CLEA, Tokyo, Japan) and tap water were available ad libitum. All mice were killed by cervical vertebra dislocation when they were 12 months old. Different tissue types were fixed in $10 \%$ neutral buffered formalin, paraffin embedded, and cut into 4- $\mu \mathrm{m}$ sections for hematoxylin and eosin staining. A portion of the liver was stored at $-70^{\circ} \mathrm{C}$ before DNA isolation. Animal studies were conducted in accordance with the Kyoto University guidelines for laboratory animal use.

\section{Immunohistochemistry}

Amyloid fibril deposition was identified by means of green birefringence in Congo red-stained sections visualized by polarizing microscopy. The amyloid fibril AApoAll was immunohistochemically identified with the avidin-biotinylated horseradish peroxidase complex (ABC) method using anti-AApoAll antiserum (Higuchi et al, 1983). The AApoAll amyloid deposition intensity was determined with the aid of the Al parameter. The Al represented the average AApoAll deposition, rated 0 to 4 , in five organ sections (liver, spleen, skin, heart, and stomach) stained with Congo red (Higuchi et al, 1983). Two observers, blinded to information regarding the tissues, independently rated and averaged the Al for each mouse.

The organ sections were also stained with antimouse perlecan antibodies (Chemicon International, Temecula, California) and anti-human sPLA2 antibodies cross-reacted with mouse homolog (Santa Cruz Biotechnology, Santa Cruz, California) by ABC method.

\section{Genotyping Microsatellite Marker Loci}

Oligonucleotide primers for microsatellite markers were purchased from Research Genetics (Huntsville, Alabama). The chromosomal position of the markers and total chromosomal length were based on guidelines in the Chromosome Committee Report (http:// www.infomatics.jax.org/ccr). Genomic DNA was extracted from the liver with the G NOME kit (BIO 101, Carlsbad, California). PCR was performed, and the products resolved on $4 \%$ agarose gels (1\% agarose and 3\% Nusieve GTG) were examined for a comparative analysis of polymorphisms in SAMP1 and A/J mice. A total of 76 markers distributed across 19 autosomal and $\mathrm{X}$ chromosomes were found to be polymorphic and used for linkage analysis. The aver- age genetic distance between two neighboring markers was $16.8 \mathrm{cM}$.

\section{Linkage Analysis}

Twelve A/J mice, 8 SAMP1 mice, $13(\mathrm{~A} / \mathrm{J} \times \mathrm{SAMP}) \mathrm{F}_{1}$ mice, $59(\mathrm{~A} / \mathrm{J} \times \mathrm{SAMP1}) \mathrm{F}_{2}$ intercrossed mice, 90 (A/J $\times$ SAMP1) $\times$ A $/ J$ backcrossed mice, and $7(A / J \times$ SAMP1) $\times$ SAMP1 backcrossed mice were generated and killed at 12 months. Their tissues were examined; mice with any pathologic findings, such as tumors, inflammation, or pneumonia, were removed from further analysis. Tissue sections were also stained with the anti-AA antiserum, and mice with $A A$ amyloid deposition were not used for the genetic analysis. As a result, $11 \mathrm{~A} / \mathrm{J}$ mice, $8 \mathrm{SAMP} 1$ mice, $13(\mathrm{~A} / \mathrm{J} \times$ SAMP1) $F_{1}$ mice, $54(\mathrm{~A} / \mathrm{J} \times \mathrm{SAMP}) \mathrm{F}_{2}$ intercrossed mice, $76(\mathrm{~A} / \mathrm{J} \times \mathrm{SAMP} 1) \times \mathrm{A} / \mathrm{J}$ backcrossed mice, and $7(\mathrm{~A} / \mathrm{J} \times$ SAMP1) $\times$ SAMP1 backcrossed mice were graded for Al and used for linkage analysis.

Linkage between individual markers and amyloid deposition (Al) was evaluated by using Map Manager QT with single-locus association and simple interval mapping methods (Manly, 1993). An LRS score of 15.2 was considered to be significant at $p=0.05$ for a recessive model in the intercross, and an LRS score of 8.8 was considered to be suggestive (Lander and Kruglyak, 1995). First, linkage analysis was performed using $(\mathrm{A} / \mathrm{J} \times \mathrm{SAMP} 1) \mathrm{F}_{2}$ intercross hybrid mice, followed by additional genotyping of loci on amyloidosislinked chromosome regions. Finally, amyloidosislinked loci were reanalyzed by using $(\mathrm{A} / \mathrm{J} \times \mathrm{SAMP} 1) \times$ $\mathrm{A} / \mathrm{J}$ backcross hybrids.

\section{Sequencing and Genotyping of Candidate Genes}

Primer pairs were designed for the sequencing of candidate genes on amyloidosis-linked chromosome regions. Tissue samples from the liver, kidney, ovary, intestine, and adipose tissues from 6-month-old SAMP1 and $\mathrm{A} / \mathrm{J}$ mice were immediately stored at $-70^{\circ} \mathrm{C}$. Messenger RNA was purified from these samples with an mRNA purification kit (QuickPrep Micro; Amersham Pharmacia Biotech, Buckinghamshire, England), after which cDNA was synthesized (First-Strand cDNA Synthesis Kit; Amersham Pharmacia Biotech). Twelve kilobases of Hspg2 cDNA, a 3-kb genomic, and $0.53 \mathrm{~kb}$ cDNA of the Pla2g2a gene were amplified with AccuTaq LA DNA polymerase (Sigma, St. Louis, Missouri), and the PCR products were purified (Ultra Clean DNA purification Kit; Bio101, Solana Beach, California) before sequencing.

The fluorescent sequencing reaction contained $4 \mu \mathrm{l}$ of PCR product, $4 \mu \mathrm{l}$ of $2.5 \mathrm{X}$ sequence buffer, $4 \mu \mathrm{l}$ of BigDye terminator cycle sequencing ready reaction $(\mathrm{ABI}), 3.68 \mu \mathrm{l}$ of distilled water, and $0.32 \mu \mathrm{l}$ of $10 \mu \mathrm{M}$ primers. Cycle sequencing was performed with 25 cycles of $96^{\circ} \mathrm{C}$ for 10 seconds, $50^{\circ} \mathrm{C}$ for 5 seconds, and $60^{\circ} \mathrm{C}$ for 4 minutes. The final reaction was separated on the ABI PRISM Genetic Analyzer 310 (PE Applied Biosystems, Foster City, California). 


\section{Function Analysis of SPLA2 on HDL Metabolism}

Three-month-old male SAMP1 and A/J mice were injected subcutaneously with $0.5 \mathrm{ml}$ of $1 \%(\mathrm{w} / \mathrm{v})$ $\mathrm{AgNO}_{3}$ to induce the acute phase reaction. Intestinal mRNA obtained at 0,24 , and 168 hours after induction was used to quantify the Pla2g2a mRNA by RT-PCR with the primers described above. Plasma obtained from mice tail veins at $0,24,48,72$, and 168 hours after induction was used for quantitative comparison of apoA-II and SAA by Western blot analysis. The quantitative Western blot analyses used anti-AApoAll (1:12,000 dilution) and anti-AA (1:8,000 dilution) antibodies. Plasma $(0.5 \mu \mathrm{l})$ was separated under reduced conditions by $15 \%$ SDS-PAGE to quantify total apoA-II and SAA and was separated under native conditions with a $2 / 15$ polyacrylamide multigel (Daiichi Pure Chemical, Tokyo, Japan) to quantify apoA-II in the HDL particles. The proteins in the gels were transferred to polyvinylidene difluoride membranes (Immobilon Transfer Membranes; Millipore, Bedford, Massachusetts) after electrophoresis. Next, the membranes were reacted with antiserum and examined with ImmunoStar Reagents (WAKO, Osaka, Japan) for the detection of chemical luminescence. X-ray film signal density was determined with the ATTO densito graph 4.1 system (ATTO, Tokyo, Japan). Nondenaturing gradient polyacrylamide gel electrophoresis was performed on 2/15 polyacrylamide multigels for HDL size comparison, and gels were subjected to electrophoresis in $25 \mathrm{~mm}$ of Tris and $192 \mathrm{~mm}$ of glycine. Before electrophoresis, lipids in plasma samples (3 $\mu \mathrm{l})$ were stained by incubation with Sudan black B dye (Higuchi et al, 1993). All data were analyzed with the Statview software package (Abacus Concepts, Berkeley, California) combined with a paired $t$ test and ANOVA (two-way ANOVA).

\section{References}

Baba S, Masago SA, Takahashi T, Kasama T, Sugimura H, Tsugane S, Tsutsui Y, and Shirasawa H (1995). A novel allelic variant of serum amyloid A, SAA1 gamma: Genomic evidence, evolution, frequency, and implication as a risk factor for reactive systemic AA-amyloidosis. Hum Mol Genet 4:1083-1087.

Benson MD, Liepnieks JJ, Yazaki M, Yamashita T, Hamidi Asl K, Guenther B, and Kluve-Beckerman B (2001). A new human hereditary amyloidosis: The result of a stop-codon mutation in the apolipoprotein All gene. Genomics 72:272-277.

Bowton DL, Seeds MC, Fasano MB, Goldsmith B, and Bass DA (1997). Phospholipase A2 and arachidonate increase in bronchoalveolar lavage fluid after inhaled antigen challenge in asthmatics. Am J Respir Crit Care Med 155:421-425.

Carlson GA, Kingsbury DT, Goodman PA, Coleman S, Marshall ST, DeArmond S, Westaway D, and Prusiner SB (1986). Linkage of prion protein and scrapie incubation time genes. Cell 46:503-511.

Castillo GM, Ngo C, Cummings J, Wight TN, and Snow AD (1997). Perlecan binds to the beta-amyloid proteins (A beta) of Alzheimer's disease, accelerates A beta fibril formation, and maintains A beta fibril stability. J Neurochem 69:24522465.
Chai CK and Lerner C (1985). The inheritance of spontaneous amyloidosis development in mice: A model for hereditary threshold metabolic disorders. Am J Med Genet 22:49-58.

Glenner GG (1980). Amyloid deposits and amyloidosis: The beta-fibrilloses. N Engl J Med 302:1283-1292.

Higuchi K, Kitado H, Kitagawa K, Kogishi K, Naiki H, and Takeda T (1993). Development of congenic strains of mice carrying amyloidogenic apolipoprotein A-II (Apoa2c): Apoa2c reduces the plasma level and the size of high density lipoprotein. FFBS Lett 317:207-210.

Higuchi K, Kitagawa K, Naiki H, Hanada K, Hosokawa M, and Takeda T (1991a). Polymorphism of apolipoprotein A-II (apoA-II) among inbred strains of mice: Relationship between the molecular type of apoA-II and mouse senile amyloidosis. Biochem J 279:427-433.

Higuchi K, Matsumura A, Honma A, Takeshita S, Hashimoto K, Hosokawa M, Yasuhira K, and Takeda T (1983). Systemic senile amyloid in senescence-accelerated mice: A unique fibril protein demonstrated in tissues from various organs by the unlabeled immunoperoxidase method. Lab Invest 48: $231-240$

Higuchi K, Naiki H, Kitagawa K, Hosokawa M, and Taketa T (1991b). Mouse senile amyloidosis: ASSAM amyloidosis in mice presents universally as a systemic age-associated amyloidosis. Virchows Arch B Cell Pathol Incl Mol Pathol 60:231-238.

Higuchi K, Yonezu T, Kogishi K, Matsumura A, Takeshita S, Higuchi K, Kohno A, Matsushita M, Hosokawa M, and Takeda T (1986). Purification and characterization of a senile amyloid-related antigenic substance (apoSASSAM) from mouse serum: apoSASSAM is an apoA-II apolipoprotein of mouse high density lipoproteins. J Biol Chem 261:1283412840.

Hurt-Camejo E, Andersen S, Standal R, Rosengren B, Sartipy P, Stadberg E, and Johansen B (1997). Localization of nonpancreatic secretory phospholipase A2 in normal and atherosclerotic arteries: Activity of the isolated enzyme on low-density lipoproteins. Arterioscler Thromb Vasc Biol 17: 300-309.

Kennedy BP, Payette P, Mudgett J, Vadas P, Pruzanski W, Kwan M, Tang C, Rancourt DE, and Cromlish WA (1995). A natural disruption of the secretory group II phospholipase A2 gene in inbred mouse strains. J Biol Chem 270:2237822385.

Kisilevsky R, Lemieux LJ, Fraser PE, Kong X, Hultin PG, and Szarek WA (1995). Arresting amyloidosis in vivo using smallmolecule anionic sulphonates or sulphates: Implications for Alzheimer's disease. Nat Med 1:143-148.

Kitagawa K, Naiki H, Takeda T, and Higuchi K (1994). Age-associated decreases in the messenger ribonucleic acid level and rate of synthesis of apolipoprotein A-II in murine senile amyloidosis. Lab Invest 70:565-571.

Koch KM (1992). Dialysis-related amyloidosis. Kidney Int $41: 1416-1429$.

Lander E and Kruglyak L (1995). Genetic dissection of complex traits: Guidelines for interpreting and reporting linkage results. Nat Genet 11:241-247.

Lyon AW, Narindrasorasak S, Young ID, Anastassiades T, Couchman JR, McCarthy KJ, and Kisilevsky R (1991). Codeposition of basement membrane components during the induction of murine splenic AA amyloid. Lab Invest 64:785-790. 
MacPhee M, Chepenik KP, Liddell RA, Nelson KK, Siracusa LD, and Buchberg AM (1995). The secretory phospholipase A2 gene is a candidate for the Mom1 locus, a major modifier of ApcMin-induced intestinal neoplasia. Cell 81:957-966.

Manly KF (1993). A Macintosh program for storage and analysis of experimental genetic mapping data. Mamm Genome 4:303-313.

Mehrabian M, Qiao JH, Hyman R, Ruddle D, Laughton C, and Lusis AJ (1993). Influence of the apoA-II gene locus on HDL levels and fatty streak development in mice. Arterioscler Thromb 13:1-10.

Naiki H, Higuchi K, Yonezu T, Hosokawa M, and Takeda T (1988). Metabolism of senile amyloid precursor and amyloidogenesis: Age-related acceleration of apolipoprotein A-II clearance in the senescence accelerated mouse. Am J Pathol 130:579-587.

Nakano T, Ohara O, Teraoka H, and Arita H (1990). Group II phospholipase A2 mRNA synthesis is stimulated by two distinct mechanisms in rat vascular smooth muscle cells. FEBS Lett 261:171-174.

Pruzanski W, de Beer FC, de Beer MC, Stefanski E, and Vadas P (1995). Serum amyloid A protein enhances the activity of secretory non-pancreatic phospholipase A2. Biochem J 309:461-464.

Pruzanski W, Stefanski E, de Beer FC, de Beer MC, Vadas P, Ravandi A, and Kuksis A (1998). Lipoproteins are substrates for human secretory group IIA phospholipase A2: Preferential hydrolysis of acute phase HDL. J Lipid Res 39:2150-2160.

Risch NJ (2000). Searching for genetic determinants in the new millennium. Nature 405:847-856.

Sartipy P, Johansen B, Camejo G, Rosengren B, Bondjers G, and Hurt-Camejo E (1996). Binding of human phospholipase A2 type II to proteoglycans: Differential effect of glycosaminoglycans on enzyme activity. J Biol Chem 271:2630726314.

Serpell LC, Sunde M, and Blake CC (1997). The molecular basis of amyloidosis. Cell Mol Life Sci 53:871-877.

Shimizu M, Higuchi K, Bennett B, Xia C, Tsuboyama T, Kasai $\mathrm{S}$, Chiba T, Fujisawa H, Kogishi K, Kitado H, Kimoto M, Takeda N, Matsushita M, Okumura H, Serikawa T, Nakamura T, Johnson TE, and Hosokawa M (1999). Identification of peak bone mass QTL in a spontaneously osteoporotic mouse strain. Mamm Genome 10:81-87.

Shimizu M, Higuchi K, Kasai S, Tsuboyama T, Matsushita M, Matsumura T, Okudaira S, Mori M, Koizumi A, Nakamura T, and Hosokawa M (2002). A congenic mouse and candidate gene at chromosome 13 locus regulating bone density. Mamm Genome 13:335-340.
Shimizu M, Higuchi K, Kasai S, Tsuboyama T, Matsushita M, Mori M, Shimizu Y, Nakamura T, and Hosokawa M (2001). Chromosome 13 locus, $\mathrm{Pbd} 2$, regulates bone density in mice. J Bone Miner Res 16:1972-1982.

Snow AD and Kisilevsky R (1985). Temporal relationship between glycosaminoglycan accumulation and amyloid deposition during experimental amyloidosis: A histochemical study. Lab Invest 53:37-44.

Tietge UJ, Maugeais C, Cain W, Grass D, Glick JM, de Beer FC, and Rader DJ (2000). Overexpression of secretory phospholipase $\mathrm{A}(2)$ causes rapid catabolism and altered tissue uptake of high density lipoprotein cholesteryl ester and apolipoprotein A-I. J Biol Chem 275:10077-10084.

Vadas P, Browning J, Edelson J, and Pruzanski W (1993). Extracellular phospholipase A2 expression and inflammation: The relationship with associated disease states. J Lipid Mediat 1-30.

Wang J, Kitagawa K, Kitado H, Kogishi K, Matsushita T, Hosokawa M, and Higuchi K (1997). Regulation of the metabolism of plasma lipoproteins by apolipoprotein A-Il. Biochim Biophys Acta 1345:248-258.

Westermark P (1998). The pathogenesis of amyloidosis: Understanding general principles. Am J Pathol 152:11251127.

Woodrow SI, Stewart RJ, Kisilevsky R, Gore J, and Young ID (1999). Experimental AA amyloidogenesis is associated with differential expression of extracellular matrix genes. Amyloid 6:22-30.

Wohlgethan JR and Cathcart ES (1979). Amyloid resistance in $\mathrm{A} / \mathrm{J}$ mice is determined by a single gene. Nature 278:453454.

Xing $Y$ and Higuchi K (2002). Amyloid fibril protein. Mech Ageing Dev 123:1625-1636.

Xing Y, Nakamura A, Korenaga T, Guo Z, Yao J, Fu X Matsushita T, Kogishi K, Hosokawa M, Kametani F, Mori M, and Higuchi K (2002). Induction of protein conformational change in mouse senile amyloidosis. J Biol Chem 277: 33164-33169. 